\title{
Analysis of Vehicle Service Queuing System Using Arena in Authorized Workshop
}

\author{
Janar Dehantoro ${ }^{1}$, Didih Sumiardi², Osep Hijuzaman ${ }^{3}$ \\ Industrial Engineering of STT.WastukancanaPurwakarta, West Java, Indonesia
}

\begin{abstract}
Almost any kind of service will form a queue. This study analyzes the queuing system of vehicle service in one of authorized workshopof well known automotive brand named Auto2000 Purwakarta, West Java, Indonesia.The queue process begin from the arrival of the customer into a service facility, waiting in the queue line services if the facility was busy serving other customers thenbeing served until finally leave the facility after completion of service. With an average unit entry 40-45 units / day, the workshop must set the service to the maximum lead time in order to accomplish the target given by the company.Due to that, this research conducted on the vehicle service queue system in the workshop to measure the performance of each service facilities in the workshop. Collecting data such as arrival time, start time and finish time of services. Data were collected at 4 service facilities those are registration, service, final inspection and billing service. This study uses the software arena to build a simulation and processing the data. The results of manual calculations show that the average waiting time services are 51.226 minutes and the average time is 129.244 minute service process so that the overall total lead time required for each customer is 180.47 minutes.
\end{abstract}

Keyword: Queue, Lead Time, Service, Arena

\section{Introduction}

Queue is something that can not be separated in everyday life. Almost any kind of service will form a queue. The process begins when the queue of customers who need the service began to come into a system, they come from a population that is called the input source. The queue process itself is a process from the arrival of the customer into a service facility, waiting in the queue line services if the facility was busy serving other customers, and then being served until finally leave the facility after completion serviced.

In its efforts to increase the satisfaction of Toyota vehicle sales then AUTO2000 continuously improve service quality service to its customers, including reducing leadtimeservice. With a target given by the company to the service process, especially in Auto2000 Purwakarta branchthan reality on the field it will be found a gap. Gap is the difference between the data obtained on conditions in the field with the given target.

Because of the problems of queuing service so a research must be conducted to analyze the problem of the queue so Auto2000 Purwakarta can provide superior service to customers.

\section{Problem Identification}

1) How to model a queuing system of service in AUTO 2000 Branch Purwakarta

2) How is the effectiveness of the service facilities in a system for the customer service process

\section{Purpose of Study}

The purpose of this study to measure the effectiveness of the queue system.

\section{Limitation of Study}

1) No rejection nor cancellation of the arrival of the customer.

2) The system queue starting from the arrival of customers into the registration service by service advisors, vehicle being repaired by mechanics and checked by the foreman then pay the bill at cashier before leaving the Auto2000.

3) No discuss the cause of the length of pelayanandalam facilities dealing with customers.

4) No discuss the specific work of each service facilities.

\section{Literature Survey}

\section{Definition of Queue}

Queue occurs in conditions when objects towards an area to be served, but then suffered a delay caused by having to experience the bustle service mechanisms. According to Bronson (1993: 308), process the queue (queuing process) is a process associated with the arrival of a customer at a service facility, then wait in a line (queue) if all services are busy, and eventually left the facility. Meanwhile, according to Heizer and Render (2005), The queues are people or goods in a row that are waiting to be served..

\section{Queuing System}

According to Gross and Harris (2001: 1-3) says that the queuing system is the arrival of the customers to get the service, waiting to be served if service facilities (server) is still busy, get service and then leave the system after being served.menumpubebandanbebasbergerakmengikutipergerak anrodaakibatsuspensikendaraan.

\section{Measuring Effectiveness of Queue}

By analyzing the size of the queue will get a lot of performance of a queuing system. Heizer and Reinder(2005) 


\section{International Journal of Science and Research (IJSR) \\ ISSN (Online): 2319-7064 \\ Index Copernicus Value (2013): 6.14 | Impact Factor (2015): 6.391}

also added a basic component queue that measures the performance of the queue. Queuing models help managers membat decision to balance the cost of service by using queuing costs include the following:

1) The average time spent by a customer in the queue.

2) The average queue length.

3) The average time spent by customers in the system (waiting time plus service time).

4) The average number of subscribers in the system.

5) The probability of service facilities will be empty.

6) System utility factor.

\section{Queuing Structure}

There are four basic models queue structure common in the entire system of the queue:

\section{1) Single Channel - Single Phase}

Single channel means there is only one track to enter service system or one service facilities. Single phase indicates that there is only one service station. After receiving the service, individuals out of the system.

\section{2) Single Channel - Multi Phase}

The term multiphase show there are two or more services are executed sequentially.

\section{3) Multi-channel systems - single phase}

Multi-channel systems - single phaseoccurs where two or more service facilities fed by a single queue.

\section{4) Multi Channel - Multi Phase}

This system shows that every system has multiple service facility at every stage so that there is more than one customer can be served at the same time.

\section{Queuing Models}

Some models of the queue by Heizer and Render (2005), among others:

1) Model A: Model single lane queue with Poisson distributed arrivals and exponential service time ( $\mathrm{M} / \mathrm{M} / 1)$. Model queues using a queue lane single lane or a service station and became the most common problem in the queuing system. Sources arrival form a single track to be served by a single station.

2) Model B: Model queue multiple lines ( $\mathrm{M} / \mathrm{M} / \mathrm{S}$ )

In the queuing model of multiple paths oftenencountered two or more lines of service stations are available for handling the customers who come. Assuming customer is waiting services form one lane and will be serviced at the service station are available first at the time. Model queue multiple phase assume that the pattern of arrivals follow a Poisson distribution and service time following the negative exponential distribution.

3) Model C: model of service time constant (M / D / 1)

Some service system has a fixed service time, and not exponentially as usual. At the time the customer according to a specific cycle as in the case of an automatic car wash queues or at the park amusement rides, delivery time occurs generally constant. This queuing model using a single queue lines with Poisson distributed arrival and service time constant.

\section{4) Model D: Model limited population}

When there is a population of potential customers that is limited to a care facility, then the model should be considered a different queue. Queuing model is different from the previous queuing model, because there is a relationship of interdependence between the long queues and the arrival rate. This queuing model using a single track.

\section{Arena}

Arena is the process-modeling and simulation software developed by Rockwell Automation and the former Systems Modeling Corporation, which was acquired by Rockwell in 2000. The software is widely used to model and simulate industrial processes and supply chains. The major value of using Arena is to anticipate the implications of designing complex processes, so as to observe a simulated performance, without first incurring the costs to build andimplement actual facilities. Arena produces Markovsystem simulations that are based on discrete events and probability distributions for entering entities into the system, and for the duration of events. The software generates reports that reflect the performance of the simulation. Arena software is taught at more than 900 universities globally, and primarily is used in Industrial Engineering and Management Science programs.

Arena has the familiar look and feel of Microsoft products. Microsoft Visio flowcharts can be imported into Arena. Arena can read from Excel and Access files and also output data to them. Specialized blocks (modules) can be used to enter Visual Basic for Applications (VBA) code into aprocess model. The student version of the software (free of charge) is available for download from the Rockwell Automation Web site, using the word STUDENT as the registration key.

\section{Methods / Approach}

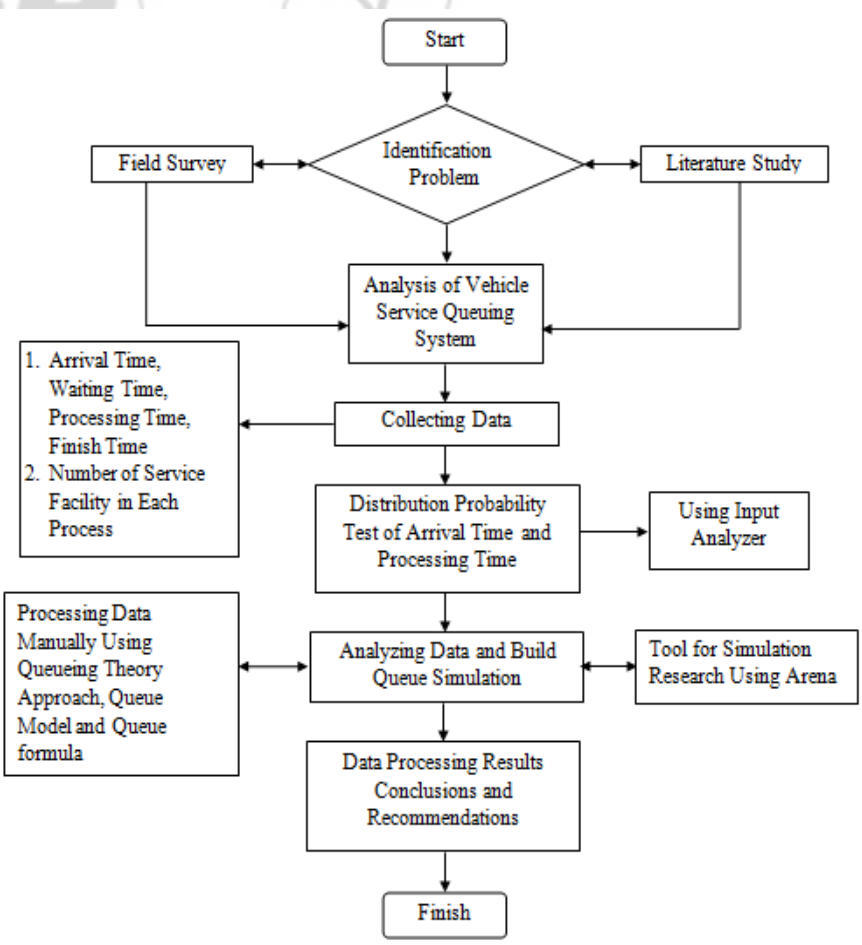

Figure 1: Methodology of Research

\section{Results/Discussion}




\section{International Journal of Science and Research (IJSR) \\ ISSN (Online): 2319-7064 \\ Index Copernicus Value (2013): 6.14 | Impact Factor (2015): 6.391}

\section{Queue Model}

Vehicle service queuing system in AUTO 2000 Purwakart used multi-channel queuing system model - multi phase.

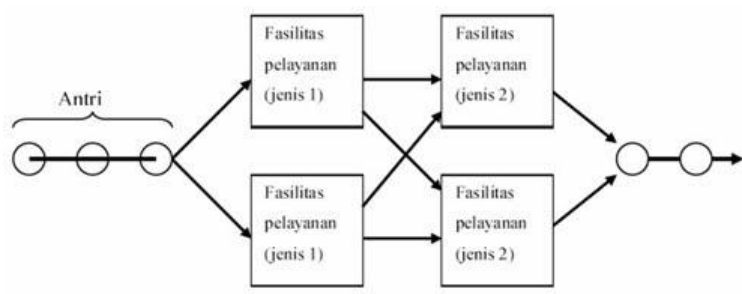

Figure 2: Multi Channel - Multi Phase

Multi-channel System - multi phase shows that every system has multiple service facility at every stage so that there is more than one customer can be served at the same time. In Auto2000 Purwakarta there are 4 service facilities that must be passed by every customer who wants to improve their vehicle. Flow process services contained in Purwakarta Auto2000 illustrated in the following figure:

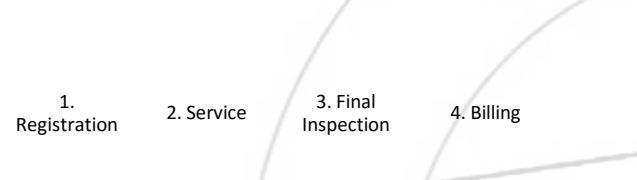

Figure 3: 4 Stages of Service Process

\section{Measuring Effectiveness of Service Facility}

\section{Service Registration}

Arrival Time

Based on survey the average time between arrival of customers $(1 / \lambda)$ are:

Note: The amount of time between the arrival of a customer $=25615$ seconds

Many customers who entered into the system queue $=43$

$(1 / \lambda)=25615 / 43=595.7 \approx 596 \mathrm{sec} /$ person

So that the arrival rate of customers $(\lambda)=6$ / hour. While the probability distribution for testing inter-arrival time is as follows:

Figure 4. Distribution Probability of Arrival Time in

Registration

\section{Processing Time}

The average service time $(1 / \mu)$ given by service personnel advisoryaitu:

Unknown: Total long service $=29615$ seconds

Many customers served $=43$

$(1 / \mu)=29615 / 43=688.7 \approx 689 \mathrm{sec} /$ person

So that the level of service $(\mu)=5.22 \approx 6 /$ hour. (leveling up)

\section{Utility}

From the average time between the arrival of the customer and the service obtained utility value $(\rho)$ as follows:

$\rho=6 /(\mathrm{s} \mu)=6 /(4 \times 5.2)=0.288 \approx 0.29$
From these data it is known that the server of 4 people found the system utilities 0.29 . This means that the server occupation is $29 \%$ of available time.

\section{Idling Probability}

Service advisor said to be idle if and only if there are no customers who lined up for registration service. The magnitude of the possibility of service advisors to be idle is:

$\mathrm{P}_{\mathrm{o}}=\frac{1}{\left(\sum_{n}^{s-1} \frac{(\lambda / \mu)^{n}}{n !}\right)+\left(\frac{\left.(\lambda / \mu)^{s}\right)}{s !\left(1-\frac{\lambda}{s \mu}\right)}\right)}$

$\mathrm{P}=\frac{1}{\left(\frac{(1.15)^{0}}{0 !}+\frac{(1,15)^{1}}{1 !}+\frac{(1,15)^{2}}{2 !}+\frac{(1,15)^{3}}{3 !}\right)+\left(\frac{(1,15)^{4}}{4 ! x(1-0,29)}\right)}$

$=\frac{1}{1+1,15+0,66+0,25+\frac{1,75}{17}}=\frac{1}{3,16}=0,316$

So it's likely no customers waiting in line was $31.6 \%$.

\section{Average Number of Customers}

The average number of customers in the queue (Lq) as follows:

$\mathrm{Lq}=\sum_{n=0}^{\infty}(\boldsymbol{n}-\boldsymbol{s}) \operatorname{Pn}=\frac{\boldsymbol{P o}\left(\frac{\lambda}{\mu}\right)^{s} \rho}{s !(1-\rho)^{2}}$

$$
\begin{aligned}
& =\frac{0,316(1,15)^{4} 0,29}{4 !(0,71)^{2}} \\
& =0,013 \approx 1 \text { customer }
\end{aligned}
$$

While the average number of customers in the system (Ls) is:

$\mathrm{L}=\lambda\left(\mathrm{Wq}+\frac{1}{\mu}\right)=\mathrm{Lq}+\frac{\lambda}{\mu}$

$=0,013+1=1,013$

Based on the above calculation, the average number of customers in the system at service vehicle registration is as much as $1,013 \approx 2$ customers.

\section{Average Waiting Time in System}

Average waiting time in queue $(\mathrm{Wq})$

$\mathrm{Wq}=\frac{L q}{\lambda}=\frac{0,013}{6}=0,002$ hour $=0,12$ minute.

So the average waiting time of all the customers who will sign up for service was 0.12 minutes while the average waiting time in the system (W)

$\mathrm{W}=\mathrm{Wq}+\frac{1}{\mu}=0,002+0,192=0,194$ hour $=11,64$ minutes

Based on the above calculation, the total average time in the system that is the time it takes customers from coming to the workshop to complete registration service is 11.64 minutes.

\section{Vehicle Service \\ Arrival Time}

Based on survey results (shown in Appendix ..) the average time between arrival of vehicles ready to be done $(1 / \lambda)$ are:

Note: The amount of time between the arrival of the vehicle $=29110$ seconds 


\section{International Journal of Science and Research (IJSR) \\ ISSN (Online): 2319-7064 \\ Index Copernicus Value (2013): 6.14 | Impact Factor (2015): 6.391}

Many of the vehicles included in the queuing system $=43$ vehicles

$(1 / \lambda)=29110 / 43=676.9 \approx 677 \mathrm{sec} /$ vehicle

So the level of vehicle to be repaired $(\lambda)=5.3 \approx 6$ vehicles / hour (leveling up).

\section{Processing Time}

Average time of service $(1 / \mu)$ required by technician is:

Note: Total processing timeof service $=260760$ seconds

Many of the vehicles are done $=43$ vehicles

$(1 / \mu)=260760 / 43=6064$ seconds $/$ vehicle

So that the level of service $(\mu) \approx 0.601$ vehicle / hour (rounded up).

\section{Utility}

From the average time between the arrival of the customer and the service obtained utility value $(\rho)$ as follows:

$\rho=\frac{\lambda}{s \mu}=\frac{6}{12 \times 0,6}=0,833$

Judging from these data it can be seen that with a total of 12 stall stall service utility system obtained at 0,833 . This means that the stall service is busy for $83.3 \%$ of available time.

\section{Idling Probability}

Stall service is said to be idle if and only if there are no vehicles waiting to be repaired. The magnitude of the possibility of a stall service idle is:

$$
\begin{aligned}
& \mathrm{P}_{\mathrm{o}} \quad=\frac{1}{\left(\sum_{n}^{s-1} \frac{(\lambda / \mu)^{n}}{n !}\right)+\left(\frac{\left.(\lambda / \mu)^{s}\right)}{s !\left(1-\frac{\lambda}{s \mu}\right)}\right)} \\
& \mathrm{P}_{\mathrm{o}}=\frac{1}{\left(\frac{(8,83)^{0}}{0 !}+\frac{(8,83)^{1}}{1 !}+\frac{(8,83)^{2}}{2 !}+\frac{(8,83)^{3}}{3 !}\right)+\left(\frac{(8,83)^{4}}{4 ! x(1-0,167)}\right)} \\
& =\frac{1}{1+8,83+38,9+114,7+\frac{6079}{4}}=\frac{1}{1683}=0,0006
\end{aligned}
$$

Average Waiting Time in System

Average wait time in queue (Wq).

$\mathrm{Wq}=\frac{L q}{\lambda}=\frac{4,53}{5,3}=0,85$ hour $=51$ minutes

So the average waiting time of all the customers who will sign up for service is 51 minutes, while the average waiting time in the system (W)

$\mathrm{Wq}+\frac{\mathbf{1}}{\boldsymbol{\mu}}=0,85+1,67=2,52$ hour $=151,2$ minutes

Based on the above calculation, the total average time in the system ie the time required vehicles ranging from finished registered service until it is accomplished by mechanical amounted to 151.2 minutes.

\section{Final Inspection}

\section{Arrival Time}

When the vehicle repaired by a mechanic the next process is the ramp test / final inspection which carried out by the foreman. When the foreman was busy then there will be stagnation time until the vehicle checked by a foreman. Based on survey results the average time between arrival of vehicles to be tested after completion service $(1 / \lambda)$ are:

Note: The amount of time between the arrival of the vehicle $=31005$ seconds

Many of the vehicles included in the queuing system $=43$ vehicles

$(1 / \lambda)=31005 / 43=721 \mathrm{sec} /$ vehicle

So that vehicles must be tested by foreman $(\lambda)=4.9 \approx 5$ vehicles / hour (leveling up).

\section{Processing Time}

The average time of final inspection $(1 / \mu)$ required by the foreman is:

Note: Total processing time final inspection $=32505$ seconds

Many of the vehicles are done $=43$ vehicles

$\left(\frac{1}{\mu}\right)=\frac{32505}{43}=755,9 \approx 756 \mathrm{detik} /$ kendaraan

\section{Utility}

From the average time between the arrival of the customer and the service obtained utility value $(\rho)$ as follows:

\section{Average Number of Customers}

The average number of customers in the queue (Lq) as follows:

$$
\begin{aligned}
\mathrm{Lq}=\sum_{\boldsymbol{n}=\mathbf{0}}^{\infty}(\boldsymbol{n}-\boldsymbol{s}) \operatorname{Pn}=\frac{\boldsymbol{P o}\left(\frac{\lambda}{\boldsymbol{\mu}}\right)^{\boldsymbol{s} \rho}}{\boldsymbol{s} !(\mathbf{1}-\boldsymbol{\rho})^{2}} \\
=\frac{0,0006(8,83)^{4} 0,833}{4 !(0,167)^{2}}=\frac{3,04}{0,67}=4,53 \approx 5
\end{aligned}
$$

vehicles.

While the average number of customers in the system (Ls) is:

$$
\begin{aligned}
& \mathrm{L}=\lambda\left(\mathrm{Wq}+\frac{\mathbf{1}}{\boldsymbol{\mu}}\right)=\mathrm{Lq}+\frac{\lambda}{\boldsymbol{\mu}} \\
& =4,53+8,83=13,36
\end{aligned}
$$

Based on the above calculation, the average number of customers in the system at the service vehicle is $13.36 \approx 14$ vehicles. $\rho=\frac{\lambda}{s \mu}=\frac{5}{4 \times 4,76}=0,263$

Judging from these data it can be seen that the four foremen who perform the final inspection system utility obtained by 0.263 . This means that the foreman occupied $26.3 \%$ of their available time.

\section{Idling Probability}

Foreman said to be idle if and only if there are no vehicles waiting to do inspection final. The magnitude of the possibility of idling foreman is:

$$
\mathrm{P}_{\mathrm{o}}=\frac{1}{\left(\sum_{n}^{s-1} \frac{(\lambda / \mu)^{n}}{n !}\right)+\left(\frac{\left.(\lambda / \mu)^{s}\right)}{s !\left(1-\frac{\lambda}{s \mu}\right)}\right)}
$$

$\mathrm{P}_{\mathrm{o}}=\frac{1}{\left(\frac{(1,05)^{0}}{0 !}+\frac{(1,05)^{1}}{1 !}+\frac{(1,05)^{2}}{2 !}+\frac{(1,05)^{3}}{3 !}\right)+\left(\frac{(1,05)^{4}}{4 ! x(1-0,263)}\right)}$ 


\section{International Journal of Science and Research (IJSR) \\ ISSN (Online): 2319-7064}

Index Copernicus Value (2013): 6.14 | Impact Factor (2015): 6.391

$=\frac{1}{1+1,05+0,55+0,19+\frac{1,215}{17,69}}=\frac{1}{2,86}=0,35$

So chances there are no vehicles waiting in line is $35 \%$.

\section{Average Number of Customers}

Average number of vehicles in the queue (Lq) as follows:

$$
\begin{aligned}
\mathrm{Lq}=\sum_{n=0}^{\infty}(\boldsymbol{n}-\boldsymbol{s}) \mathrm{Pn}=\frac{\boldsymbol{P o}\left(\frac{\lambda}{\mu}\right)^{s} \boldsymbol{\rho}}{\boldsymbol{s} !(\mathbf{1}-\boldsymbol{\rho})^{2}} \\
=\frac{\mathbf{0 , 3 5}(\mathbf{1 , 0 5})^{4} \mathbf{0 , 2 6 3}}{\mathbf{4} !(\mathbf{0 , 7 4})^{2}}=\frac{\mathbf{0 , 1 1}}{\mathbf{1 3 , 1 4}}=0,008 \approx 0 \text { vehicle. }
\end{aligned}
$$

While the average number of vehicles in the system (Ls) is:

$\mathrm{L}=\lambda\left(\mathrm{Wq}+\frac{1}{\mu}\right)=\mathrm{Lq}+\frac{\lambda}{\mu}$

$=0,008+1,05=1,058 \approx 2$ vehicles.

Based on the above calculation, the average number of vehicles in the queuing system final inspection is as much as 2 vehicles.

Average Waiting Time in System

Average wait time in queue (Wq)

$\mathrm{Wq}=\frac{\boldsymbol{L q}}{\lambda}=\frac{\mathbf{0 , 0 0 8}}{\mathbf{5}}=0,0016$ hour $=0,096$ minutes

So the average waiting time of all vehicles will be checked by the foreman is 0,010 minutes, while the average waiting time in the system (W).

$\mathrm{W}=\mathrm{Wq}+\frac{\mathbf{1}}{\boldsymbol{\mu}}=0,0016+0,211=0,2111$ hour $=12,66$ minutes

\section{Billing}

Arrival Time

When the vehicle completed the final inspection by the foreman, the last stage is the creating bill by cashier. When the bill has been completed, the vehicle's owner will be called upon to make payments at checkout counters. Based on survey results, the average time between arrival of work order should be made receipt service $(1 / \lambda)$ are:

Note: The amount of time between the arrival of the vehicle $=30170$ seconds

Many work order in the system queue $=43$ Work Order $(1 / \lambda)=30170 / 43=701 \mathrm{sec} /$ vehicle

Work Order should be made so that the receipts $(\lambda)=5.14 \approx$ $6 \mathrm{WO} /$ hours (leveling up).

\section{Processing Time}

Average time billing $(1 / \mu)$ required by that is:

Unknown: Total processing time billing $=12542$ seconds

Number of Work Order $=43 \mathrm{WO}$

$(1 / \mu)=12542 / 43=291.7 \approx 292 \mathrm{sec} / \mathrm{PKB}$

Then the service level $(\mu) 12.32 \approx 13 \mathrm{WO} /$ hour (leveling up).

\section{Utility}

From the average time between the arrival of the customer and the service obtained utility value $(\rho)$ as follows:

$\rho=\lambda /(\mathrm{s} \mu)=(5.14) /(1 \times 12.32)=0.417$
Judging from these data it can be seen that by 1 kasiryang working on creating system utility receipts obtained by 0.417 . This means that cashier occupation is $41.7 \%$ of the time.

\section{Idling Probability}

The cashier said to be idle if and only if there is no WO queuing to be made to bill. The magnitude of the possibility of unemployed cashier is:

$$
\mathrm{P}_{\mathrm{o}}=\frac{1}{\left(\sum_{n}^{s-1} \frac{(\lambda / \mu)^{n}}{n !}\right)+\left(\frac{\left.(\lambda / \mu)^{s}\right)}{s !\left(1-\frac{\lambda}{s \mu}\right)}\right)}
$$

$$
\begin{aligned}
& \mathrm{P}_{\mathrm{o}}=\frac{1}{\left(\frac{(0,417)^{\mathbf{0}}}{0 !}+\frac{(\mathbf{0 , 4 1 7})^{1}}{1 !}+\frac{(0,417)^{2}}{2 !}+\frac{(0,417)^{3}}{3 !}\right)+\left(\frac{(0,417)^{4}}{4 ! x(1-0,417)}\right)} \\
& =\frac{1}{1+0,417+0,087+0,012+\frac{0,03}{14}}=\frac{1}{1,518}=0,658
\end{aligned}
$$

So chances are no vehicles waiting in line is $65.8 \%$.

\section{Average Number of Customers}

The average amount of WO in the queue (Lq) as follows:

$$
\mathrm{Lq}=\sum_{n=0}^{\infty}(\boldsymbol{n}-\boldsymbol{s}) \operatorname{Pn}=\frac{\boldsymbol{P o}\left(\frac{\lambda}{\mu}\right)^{s} \boldsymbol{\rho}}{\boldsymbol{s} !(1-\boldsymbol{\rho})^{2}}
$$

$$
\begin{aligned}
& =\frac{\mathbf{0 , 6 5 8}(0,417)^{4} \mathbf{0 , 4 1 7}}{4 !(0,583)^{2}} \\
& =\frac{\mathbf{0 , 0 0 8}}{\mathbf{8 , 1 6}}=0,0009 \approx 0 \mathrm{pkb}
\end{aligned}
$$

While the average amount of WO in the system (Ls) is:

$\mathrm{L}=\lambda(\mathrm{Wq}+1 / \mu)=\mathrm{Lq}+\lambda / \mu$

$=0.0009+0.417=0.1479 \approx 1 \mathrm{WO}$

Based on the above calculation, the average amount of WO in the queuing system billing / payment is as much as 1 WO.

\section{Average Waiting Time in System}

Average wait time in queue (Wq) $\mathrm{Wq}=\frac{\boldsymbol{L q}}{\boldsymbol{\lambda}}=\frac{\mathbf{0 , 0 0 0 9}}{\mathbf{5 , 1 4}}=0,00017$ hour $=0,010$ minutes

So the average waiting time of all WO will be made to be bill by cashier is 0,010 minutes while the average waiting time in the system $(\mathrm{W})$

$\mathrm{W}=\mathrm{Wq}+1 / \mu=0.00017+0.0811=0.8127 \mathrm{~h}=4.87$ minutes

\section{QUEUE SIMULATION}

Simulation method is a effective method to solve this kind of queue problem. To make the simulation of a random time of arrival and the time service. This study will use the software arena 


\section{International Journal of Science and Research (IJSR) \\ ISSN (Online): 2319-7064}

Index Copernicus Value (2013): 6.14 | Impact Factor (2015): 6.391

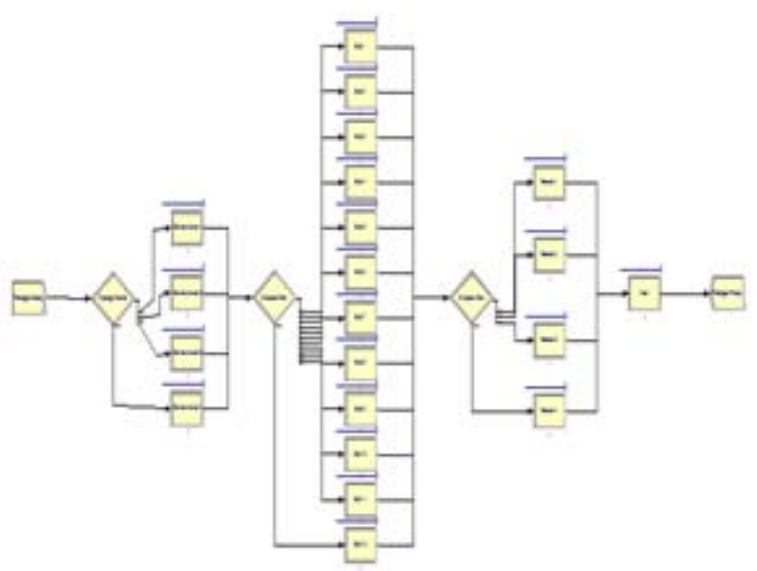

Figure 4: Queue Simulation Made In Arena

\section{Conclusion}

From the observation and analysis has been done it was concluded that:

1) System service queue reception service vehicles in Purwakarta AUTO2000 a multi-channel queuing system - single phase with the notation kendall $(\mathrm{G} / \mathrm{G} / \mathrm{s})$.

2) Effectiveness of the best services are at stall service with utility services ( $\rho$ ) $83.3 \%$ to the level of unemployed server $\left(\mathrm{P}_{\mathrm{o}}\right) \quad 0.06 \%$. As for the service of service advisors and final inspection should be increased because it has low system utility that is $29 \%$ and $26.3 \%$.

3) Lead time to service stall service contributed most to the long lead time service vehicles in Auto2000 Purwakartawith an average time in the system (Ws) amounted to 151.2 minutes, or $83 \%$ of total lead time overall.

4) The simulation model can be presented with a good arena of real conditions that exist in the field but has a different calculation results with the results of manual calculations.

\section{Suggestions}

From the observations made by the author, it may put forward suggestions as follows:

1) In order for the company to further improve service vehicle services primarily toserving vehicle at stall service to reduce it's lead time

2) It is expected that in future studies may use more than one device simulation in order to obtain more accurate comparison.

\section{References}

[1] Djauhari, \&Maman A. 1990. StatistikMatematik. Bandung : InstitutTeknologi Bandung.

[2] Gross, D. Harris, C.M. 1998. Fundamental of Queueing Theory, Third Edition, Canada : John Wiley.

[3] Bronson, R. 1993. TeoridanSoal- Soal Operational Research. Jakarta: PT. GeloraAksaraPratama.

[4] Farkhan, Feri. 2013. AplikasiTeoriAntriandanSimulasipadaPelayanan Teller Bank. Semarang : UniversitasNegeri Semarang.
[5] Ginting $\mathrm{P}$. Lajor. 2013. AnalisisSistemAntriandanOptimalisasiLayanan Teller. Semarang : UniversitasDiponegoro.

[6] Kakiay, T.J. 2004. DasarTeoriAntrianuntukKehidupanNyata. Yogyakarta : Andi.

[7] Mulyono, Sri. 2002. RisetOperasi. Jakarta : FakultasEkonomiUniversitas Indonesia.

[8] Ardiana, Nuke Maya. 2010. DesainAkses Optimum danSistemEvakuasiSaatKondisiDaruratPada KM. SinarBintan . Surabaya : InstitutTeknologiSepuluh November.

\section{Author Profile}

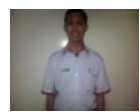

Janar Dehantoro, received the ST. from Industrial Engineering STT. Wastukancana Purwakarta, West Java, Indonesia.

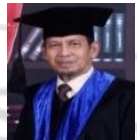

Didih Sumiardi received the S.T., M.M., Lecture of Industrial Engineering STT. Wastukancana Purwakarta, West Java, Indonesia. I had studied postgraduate in Mechanical Engineering of STT. Mandala in Bandung (2003) and Magister Management Production from MercuBuana University (2006).

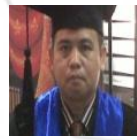

Osep Hijuzaman received the S.Pd, M.T, Lecture of STT. Wastukancana Purwakarta, West Java, Indonesia. I had studied postgraduate in Electrical Engineering Educationfrom University of Indonesia in Bandung (1999) and Magister Industrial Engineering and Management from Pasundan University (2007), now studying at the University of Indonesia in Bandung, Doctoral Program in Management of Science. 